\title{
DEVELOPMENT OF A KINETIC SPECTROPHOTOMETRIC METHOD FOR THE DETERMINATION OF CICLOPIROX OLAMINE IN PHARMACEUTICAL SAMPLE
}

\author{
FALLON NACARATTE ${ }^{2}$, M. INÉS TORAL ${ }^{2}$ AND CÉSAR SOTO*1 \\ ${ }^{1}$ Department of Analytical and Inorganic Chemistry, Faculty of Chemical Sciences, University of Concepción, PO Box: 160-C, Concepción, Chile \\ ${ }^{2}$ Department of Chemistry, Faculty of Sciences, University of Chile, PO Box: 653, Santiago, Chile.
}

\begin{abstract}
S
A simple and sensitive kinetic spectrophotometric method was developed for the determination of ciclopirox olamine in pharmaceutical formulations (cream). The method is based on the oxidation of ciclopirox olamine with $\mathrm{KMnO}_{4}$ in alkaline medium to form $\mathrm{K}_{2} \mathrm{MnO}_{4}$, a bluish green color compound, at ionic strength controlled and room temperature. The reaction is monitored measuring the rate of change of absorbance at $610 \mathrm{~nm}$. The absorbance-concentration plot corresponding to synthetic pharmaceutical samples (cream) was rectilinear, over the range of $0.32-10.0 \mu \mathrm{g} \mathrm{mL}^{-1}$, with detection and quantification limits of 0.095 $\mu \mathrm{g} \mathrm{mL} L^{-1}$ and $0.32 \mu \mathrm{g} \mathrm{mL}^{-1}$, respectively. Different experimental parameters affecting the development and stability of the reaction product were carefully studied via factorial screening and optimized by univariate method. The determination of ciclopirox olamine by the fixed time method is feasible and more advantageous with the calibration equation obtained at $30 \mathrm{~min}$. The proposed method was validated for the application of the determination of the drug in pharmaceutical sample (cream).
\end{abstract}

Keywords: kinetic, spectrophotometric, ciclopirox olamine.

\section{INTRODUCTION}

Ciclopirox olamine (CXO), 6-cyclohexyl-1-hydroxy-4methyl-2(1H)pyridona is a synthetic hydroxypyridone, with fungicide action of broadspectrum that inhibits the growth of pathogenic dermatophytes (skin fungi, hair and nail) ${ }^{1,2,3}$. This drug has a half-life of $1.7 \mathrm{~h}$ and renal excretion. Studies with human skin of corpses showed capillar penetration through the epidermis to the hair follicles and sebaceous glands, while a portion of the drug remains in the stratum corneum ${ }^{4}$ and it presents systemic absorption when applied in cream $1 \%(\mathrm{CXO})$. The mechanism of action is related to its chelating action on polyvalent metal cations such as $\mathrm{Fe}$ (III) and $\mathrm{Al}$ (III) essential for two fungus enzymes, catalase and peroxidase ${ }^{2,5}$. The USP has published two standard methods for the determination of CXO in pharmaceutical formulations, by HPLC $^{6}$ and spectrophotometry ${ }^{7}$. Other methods reported include, HPLC 8,9 $\mathrm{LC}^{10}$ in raw material and lotions; micro-liquid chromatography ${ }^{11}$ in topical formulations; spectrofluorimetry ${ }^{12}$, amperometry in flow and batch injection systems ${ }^{13}$, polarography ${ }^{14,15}$, micellar electrokinetic capillar chromatography ${ }^{16}$ and capillar electrophoresis with capacitively coupled contactless conductivity detection ${ }^{17}$ in pharmaceutical formulations; and LC/MS/MS in human nail 18. The development of new analytical methods requires accurate results and sensitivity in the analytical determination, and therefore are mostly used methods of high cost and technical complexity from this perspective is important to develop inexpensive methods such as kinetic spectrophotometry, these methods has comparable levels of accuracy and sensitivity to the methods above mentioned ${ }^{19}$. Only few works in analytical procedures based on kinetics especially for pharmaceutical in biological fluids has been published in the last decade ${ }^{20}$. Furthermore, these methods present sensitivities selective due to the measurement of the increase in the absorbance in time function instead of the measurement of an only one absorbance value ${ }^{21}$. This work describes the development and validation of kinetic spectrophotometric methods for the quantification of CXO in pharmaceutical formulations (cream), using the monitoring of the reduction of $\mathrm{KMnO}_{4}$ with $\mathrm{CXO}$ in alkaline medium. In this reaction, the absorption band between 570 and $650 \mathrm{~nm}$ increases, this band corresponds to manganate $\left(\mathrm{K}_{2} \mathrm{MnO}_{4}\right)$, the product of reduction of $\mathrm{KMnO}_{4}{ }^{22}$. Consequently, it was found that the generation of this product is in function of the time and concentration of the reactants; this shows its analytical usefulness and develops a reliable and specific kinetic spectrophotometric method for the determination of CXO in pharmaceutical samples.

\section{EXPERIMENTAL}

\subsection{Instruments}

A Shimadzu UV-1603 double beams spectrophotometer with $10 \mathrm{~mm}$ quartz cells was used for measurement of the absorbance. For all solutions, the spectra were recorded on the range between 190-800 nm against blank, using sampling intervals of $0.2 \mathrm{~nm}$ with a scan speed of $480 \mathrm{~nm} \mathrm{~min}{ }^{-1}$. The spectral data were processed by Shimadzu software kit Ver. 3.7 (P/N 206-60570-04). The $\mathrm{pH}$ measurements were realized with Oyster ${ }^{\mathrm{TM}} \mathrm{pH}$ Meter (Measures $\mathrm{pH}$ : 0.00 to $14.00 ; \mathrm{pH}$ Accurate to 0.02 and $\mathrm{pH}$ and resolution of 0.01 ), before and after each one of the assays carried out. The solid samples were weighted with $\mathrm{a} \pm 0.01 \mathrm{mg}$ of uncertainty using a Sartorius R 200D balance.

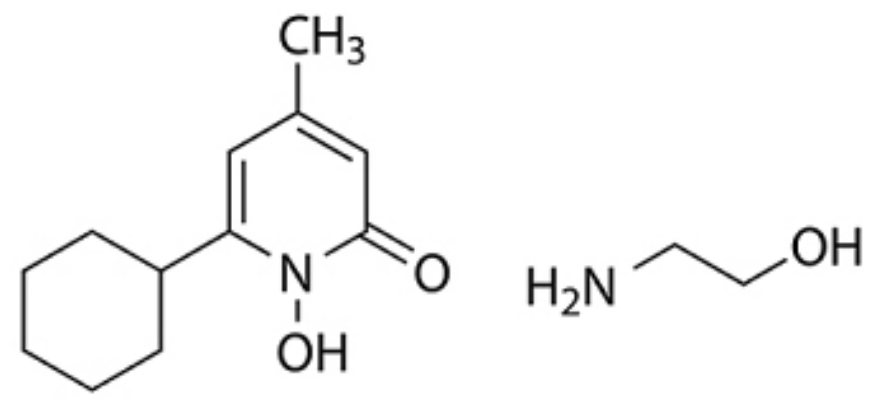

Figure 1. Ciclopirox olamine (CXO).

\subsection{Reagents}

CXO was purchased from Sigma-Aldrich ${ }^{\circledR}$, all reagents were of analytical reagent grade and all solutions were prepared with Milli-Q water. Stock solutions of $1.0 \times 10^{-3} \mathrm{~mol} \mathrm{~L}^{-1}$ of CXO was prepared by dissolving $15.0 \mathrm{mg}$ and diluted to $50 \mathrm{~mL}$ in $\mathrm{NaOH} 0.01 \mathrm{~mol} \mathrm{~L}^{-1}$. The same solution was used to prepare other ranges of concentrations by appropriate dilution using the same $\mathrm{NaOH}$ solution. $\mathrm{KMnO}_{4} 0.02 \mathrm{~mol} \mathrm{~L}^{-1}$ aqueous solution was used. $\mathrm{NaOH} 2.0 \mathrm{~mol} \mathrm{~L}^{-1}$ aqueous solution was prepared.

\section{PROCEDURES} used.

All assays were realized by triplicate and amber calibrated flasks were

\subsection{Preliminary studies}

The studies of $\mathrm{CXO}-\mathrm{KMnO}_{4}$-system were realized using: $\mathrm{pH} 12.0$-13.5 (With adequate $\mathrm{NaOH}$ solution); $\mathrm{Na}_{2} \mathrm{SO}_{4}$ concentration: $0.0-0.7 \mathrm{~mol} \mathrm{~L}^{-1}$; $\mathrm{KMnO}_{4}$ concentration: $5.0 \times 10^{-4}-0.001 \mathrm{~mol} \mathrm{~L}^{-1}$; reaction time: $0-120 \mathrm{~min}$ and CXO $1.0 \times 10^{-5} \mathrm{~mol} \mathrm{~L}^{-1}$. The absorption spectra were realized between 190 and $800 \mathrm{~nm}$ at room $\mathrm{T}^{\circ}$. 


\subsection{Kinetic procedure}

The complete kinetic measurements were performed under pseudo first order conditions. The $\mathrm{KMnO}_{4}$ was used in excess over $\mathrm{CXO}$, at $\mathrm{pH}$ and $\mathrm{Na}_{2} \mathrm{SO}_{4}$ concentration (ionic strength), of 13.2 and $0.6 \mathrm{~mol} \mathrm{~L}^{-1}$, respectively. The temperature was maintained at $20 \pm 0.1^{\circ} \mathrm{C}$. The course of the reaction was followed by monitoring the increase in the absorbance at $610 \mathrm{~nm}\left(\mathrm{~K}_{2} \mathrm{MnO}_{4}\right)$. To a series of $5 \mathrm{~mL}$ volumetric amber flasks, were added adequate aliquots of $2.0 \mathrm{~mol} \mathrm{~L}^{-1} \mathrm{NaOH}$ solution, $0.02 \mathrm{~mol} \mathrm{~L}^{-1} \mathrm{KMnO}_{4}$ solution and $2.0 \mathrm{~mol} \mathrm{~L}^{-1}$ $\mathrm{Na}_{2} \mathrm{SO}_{4}$ solution and aliquots of CXO $1.0 \times 10^{-3} \mathrm{~mol} \mathrm{~L}^{-1}$ over the concentration range $1.0 \times 10^{-6}$ to $13.0 \times 10^{-6} \mathrm{~mol} \mathrm{~L}^{-1}$ and dilute to the mark with Milli-Q water; then mix all flasks for $30 \mathrm{~min}$ and measure the absorbance at $610 \mathrm{~nm}$ against an appropriate blank prepared simultaneously. Plot absorbance values v/s drug concentrations to prepare calibration graph, measured at a fixed time of $30 \mathrm{~min}$ the corresponding regression equation was derived. Furthermore $\log \mathrm{v} v / \mathrm{s} \log$ $[\mathrm{CXO}]$ was plotted to get the order of the reaction at $30 \mathrm{~min}$.

\subsection{Factorial study parameters}

It was performed using a factorial design, with a Statistical software (Statgraphics Centurion XV for Windows, Rockville, MD). A factorial screening design $2^{4}$, with 6 centers and 1 replica was used, at $1.0 \times 10^{-5} \mathrm{~mol} \mathrm{~L}^{-1}$ CXO concentration, the parameters studied were: $\mathrm{pH}$ (13 to 13.2 with adequate volume of $\mathrm{NaOH}$ solution $), \mathrm{Na}_{2} \mathrm{SO}_{4}$ concentration $\left(0.1-0.5 \mathrm{~mol} \mathrm{~L}^{-1}\right)$, reaction time (15 - $30 \mathrm{~min})$ and $\mathrm{KMnO}_{4}$ concentration $\left(8.0 \times 10^{-4}-1.0 \times 10^{-3} \mathrm{~mol} \mathrm{~L}^{-1}\right)$. The analyte solutions were prepared in a volume of $5 \mathrm{~mL}$ and reaction monitoring at $610 \mathrm{~nm}$.

3.4. Procedure for Determination of $\mathrm{CXO}$ in pharmaceutical formulation (cream)

Preparation of synthetic pharmaceutical formulation (cream) sample. A simulated sample was prepared by weighing the following reagents: $0.98 \mathrm{mg}$ of benzoic acid, $30.5 \mathrm{mg}$ of cetyl alcohol, liquid petrolatum $152.5 \mathrm{mg}, 87.5 \mathrm{mg}$ of distilled water, $30.5 \mathrm{mg}$ of monostearate of glycerol and $3.05 \mathrm{mg}$ CXO. The preparation consisted initially in to heat the liquid petrolatum at $70 \pm 3^{\circ} \mathrm{C}$, then the drug is added and was stirred for 30 minutes, then the sample was allowed to stand in refrigerator until pulping. The same procedure was performed for a blank.

CXO extraction procedure. The cream contains analyte $(1 \%)$ as the salt, ciclopirox olamine (Micopirox ${ }^{\mathrm{TM}}$ Lab. Cassara Chile). The drug extraction was conducted by adding $50 \mathrm{~mL}$ of acetonitrile to $0.300 \mathrm{~g}$ of sample and was stirred for $1 \mathrm{~h}$ at $5^{\circ} \mathrm{C} \pm 0.5^{\circ} \mathrm{C}$, the content was vacuum filtered $(0.45 \mathrm{~mm}$ PVDF filter). The solution was left for $1 \mathrm{~h} 30 \mathrm{~min}$ in a freezer at a temperature close to $0^{\circ} \mathrm{C}$, then filtered through syringe filter with Nylon membrane (pore diameter of $0.20 \mathrm{~mm}$ ). The supernatant was dried under $\mathrm{N}_{2}$ flow and was reconstituted in $0.01 \mathrm{~mol} \mathrm{~L}^{-1} \mathrm{NaOH}$ solution to a final volume of $100 \mathrm{~mL}$.

\section{RESULTS AND DISSCUSIONS}

For the determination of $\mathrm{CXO}$, through the development of a kinetic method, $\mathrm{KMnO}_{4}$ was using as the oxidant. Taking into account the redox properties of $\mathrm{KMnO}_{4}$, it chose to work in the alkaline $\mathrm{pH}$ range because the

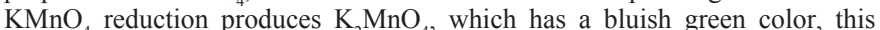
reaction is mono-electronic and has moderate oxidizing character, these factors favor the development of analytical kinetic methods. In this context and in order to study the stability of the drug, their spectra were evaluated in a range of $\mathrm{pH}$ from 12.0 to 13.5 and after $2 \mathrm{~h}$ stirring, finding a defined band at $310 \mathrm{~nm}$. The spectrum of oxidant presented the absorption bands in the following ranges: 400 to $470 \mathrm{~nm}$ and 570 to 650 , the latter shown defined and with a maximum centered at $610 \mathrm{~nm}$, these bands grow the same time with the $\mathrm{pH}$. However, values of $\mathrm{pH}>13.5$, produce displacement and increase of bands at 430 and $610 \mathrm{~nm}$ over than expected. This can attributable to absorption of $\mathrm{K}_{2} \mathrm{MnO}_{4}$. This phenomenon is favored at these $\mathrm{pH}$ values, because of self-destruction of $\mathrm{KMnO}_{4}$, increasing the concentration of $\mathrm{K}_{2} \mathrm{MnO}_{4}$ formed through the mechanism proposed by Jezowska ${ }^{23}$. In this context, the development of a kinetic method is restricted to the $\mathrm{pH}$ range, 12.0 to 13.3 , which was studied. In first instance, $\mathrm{pH} 13.2$ was selected and the reaction time was studied between 0 and $120 \mathrm{~min}$ (Figure 2). The equilibrium is not reached even in the maximum reaction time studied, this result does not provide adequate conditions for analytical purposes, for this reason $30 \mathrm{~min}$ was selected as reaction time for the following studies. Spectrograms of the reaction between $\mathrm{CXO}$ and $\mathrm{KMnO}_{4}(\mathrm{pH}$ 13.2), in function of the reaction time and the concentration of $\mathrm{Na}_{2} \mathrm{SO}_{4}$, individually, showed changes in the spectral signals of $\mathrm{KMnO}_{4}$, demonstrating that the analyte oxidation is performed by $\mathrm{KMnO}_{4}$ action. From the temperature $\left(\mathrm{T}^{\circ}\right)$ effect studies at $20^{\circ} \mathrm{C}$ and $80^{\circ} \mathrm{C}$, it was established that the appropriate value of $\mathrm{T}^{\circ}$ for monitoring the reaction was $20^{\circ} \mathrm{C}\left(\right.$ room $\mathrm{T}^{\circ}$ ), because the higher $\mathrm{T}^{\circ}$ can produce the precipitation of $\mathrm{MnO}_{2}$. The effect of stirring also was studied, it found that increases the course of the oxidation of $\mathrm{CXO}$ with $\mathrm{KMnO}_{4}$. Therefore, the stirring was chosen for all work. The light favors the autodecomposition of the $\mathrm{KMnO}_{4}$, for this reason amber calibrated flasks were used.

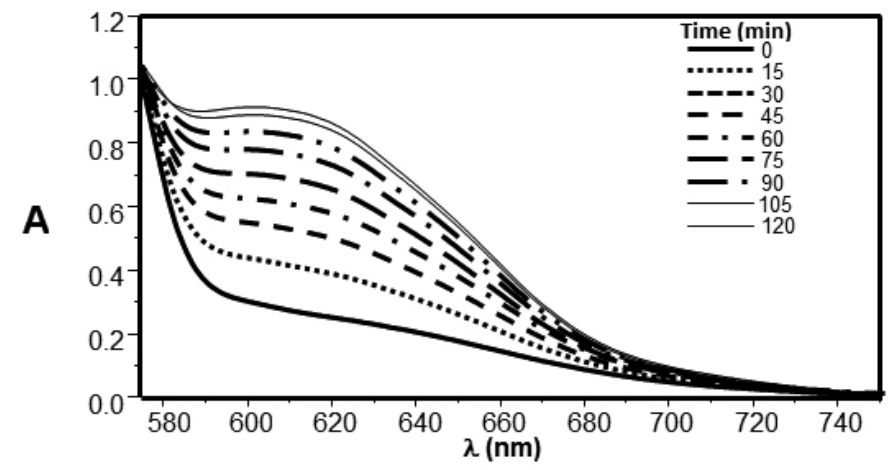

Figure 2. Absorption spectra of the following $\mathrm{CXO}-\mathrm{KMnO}_{4}$-system. Experimental conditions, CXO 1.0x $10^{-5} \mathrm{~mol} \mathrm{~L}^{-1}, \mathrm{KMnO}_{4} 1.0 \times 10^{-3} \mathrm{~mol} \mathrm{~L}^{-1}, \mathrm{pH}$ 13.2 , room $\mathrm{T}^{\circ}$ and reaction time between 0 and $120 \mathrm{~min}$.

A factorial "screening" study was designed to determine the principal experimental factors in the oxidation of $\mathrm{CXO}$ with $\mathrm{KMnO}_{4}$. The factors considered were: reaction time, oxidant concentration, $\mathrm{pH}^{4}$, and $\mathrm{Na}_{2} \mathrm{SO}_{4}$ concentration (ionic strength). According to the respective procedure, these factors were evaluated by an experimental design of $2^{4}$ with six centers and one replica, monitoring at $610 \mathrm{~nm}$ (Figure 3). All variables were statistically significant $(\mathrm{p}<0.05)$, but the $\mathrm{Na}_{2} \mathrm{SO}_{4}$ concentration present greater effect on the reaction. The influence of the factors set out as significant, do not fit a normal distribution (Figure 3). Therefore, according to the "screening" factorial analysis, all factors should be considered in the optimization of the reaction by the univariate method.

Standardized Pareto Chart

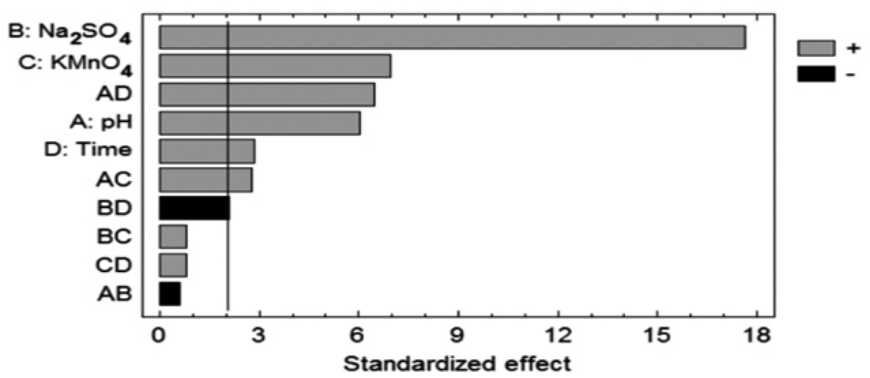

Figure 3. Selection of factors in the oxidation of CXO with alkaline $\mathrm{KMnO}_{4}$. Standardized Pareto chart.

\subsection{Optimization of Variables}

According to the results of preliminary and factorial "screening" studies the experimental parameters were carefully studied and optimized. These include, reaction time, oxidant concentration, $\mathrm{pH}$, and $\mathrm{Na}_{2} \mathrm{SO}_{4}$ concentration (ionic strength). Such factors were changed individually while the others were kept constant, and the constant values used were, $30 \mathrm{~min}, 8.0 \times 10^{-4} \mathrm{molL}^{-1}, 13.2$ and $0.6 \mathrm{molL}^{-1}$, respectively. The reaction monitoring was carried out at 610 $\mathrm{nm}$ using CXO $1.0 \times 10^{-5} \mathrm{molL}^{-1}$ and room temperature.

Time effect. Using the experimental conditions detailed above, this study was carried out between 0 and $120 \mathrm{~min}$ and in this interval the absorbance at $610 \mathrm{~nm}$ increased, indicating that the equilibrium is not reached even in the maximum reaction time, this result does not provide adequate conditions for analytical purposes, however $\mathrm{t}=30 \mathrm{~min}$ represents a convenient value, because the corresponding absorbance values are significant and coherent, being proportional to the analyte concentration changes. Therefore, $30 \mathrm{~min}$ was selected for further studies.

pH effect. The influence of $\mathrm{pH}$ in alkaline range on the reaction was studied between 12.0 and 13.5. It was found that increasing of the $\mathrm{pH}$ value 
resulted in a corresponding increase in the absorbance of the reaction product. It was observed that the most significant variation begins at $\mathrm{pH}=13.0$. Thus, 13.2 was established as the most suitable $\mathrm{pH}$ value for this study (Figure 4).

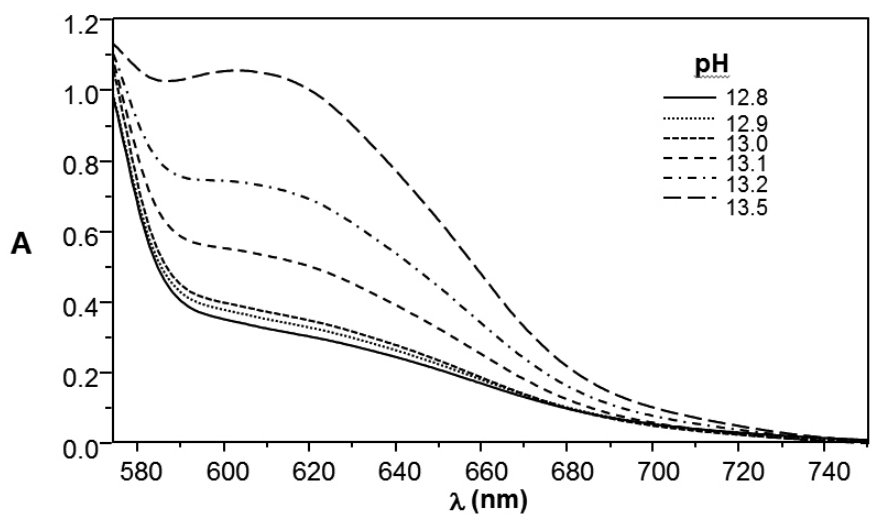

Figure 4. Absorption spectra of $\mathrm{pH}$ effect on the CXO-KMnO${ }_{4}$-system. Experimental conditions: The $\mathrm{pH}$ values were maintained with adequate volume of $\mathrm{NaOH}$ solutions, $\mathrm{CXO} 1 \times 10^{-5} \mathrm{~mol} \mathrm{~L}^{-1}, \mathrm{KMnO}_{4} 8.0 \times 10^{-4} \mathrm{~mol} \mathrm{~L}^{-1}$, room $\mathrm{T}^{\circ}, \mathrm{Na}_{2} \mathrm{SO}_{4} 0.6 \mathrm{~mol} \mathrm{~L}^{-1}, 30 \mathrm{~min}$ of reaction time at $610 \mathrm{~nm}$.

KMnO concentration effect. This effect was studied over the range of $5.0 \times 10^{-4}$ to $10.0 \times 10^{-4} \mathrm{~mol} \mathrm{~L}^{-1}$ of $\mathrm{KMnO}_{4}$. It was found that, increasing of oxidant concentration causes a gradual increase without reaching a constant value of absorbance between 590 and $650 \mathrm{~nm}$. Because, the concentration $8.0 \times 10^{-4} \mathrm{~mol}$ $\mathrm{L}^{-1}$ presented greater separation of signals and less deviation between the data, was selected as the oxidant concentration for this work.

$\mathrm{Na}_{2} \mathrm{SO}_{4}$ concentration effect (ionic strength). For investigating the influence of this parameter on reaction performance, several experiments were performed by adding or not of $\mathrm{Na}_{2} \mathrm{SO}_{4}$ solution using the following concentration range of 0.1 to $0.7 \mathrm{~mol} \mathrm{~L}^{-1}$. The results show that the salt addition had significant impact in the spectral signal. An increase in absorbance of the spectral signals was observed for $\mathrm{Na}_{2} \mathrm{SO}_{4}$ concentrations from 0.5 to $0.7 \mathrm{~mol}$ $\mathrm{L}^{-1}$. Only this study was carried out with 3 concentrations values of $\mathrm{CXO}(7 \times 10$ ${ }^{6}, 1 \times 10^{-5}$ and $4 \times 10^{-5} \mathrm{~mol} \mathrm{~L}^{-1}$ ) because the experimental answer was unclear when the use only one value. The better linearity and low spread between absorbance data corresponding to $0.6 \mathrm{~mol} \mathrm{~L}^{-1}$, this value was selected.

\subsection{Stoichiometry Determination}

The limit logarithmic method ${ }^{24}$ was used for study of the reaction stoichiometry with the experimental conditions selected above and monitoring the reaction at $610 \mathrm{~nm}$. The plots corresponding to $\log \mathrm{A} \mathrm{v} / \mathrm{s} \log \left[\mathrm{KMnO}_{4}\right]$ at a constant value of $[\mathrm{CXO}]$ and $\log \mathrm{A} \mathrm{v} / \mathrm{s} \log [\mathrm{CXO}]$ at constant value of $\left[\mathrm{KMnO}_{4}\right]$, gave straight lines with slopes 1.194 and 0.681 , respectively. Thus, the molar ratio of the reaction is $(1.194: 0.681)=(2: 1)$. Taking into accoun the stoichiometric ratio and the chemical behavior of both reactants in alkaline medium. Is possible infer that the reaction proceeds in two steps, where the second is the rate-determining step. This process seems produce the formation of carboxylic acid from the alcoholic group of the analyte.

\subsection{Kinetic of the reaction}

Using the optimal physicochemical values and pseudo-first order conditions where $\mathrm{KMnO}_{4}$ used was at least 10 fold over the CXO concentration, the absorbance-time signals were monitoring at $610 \mathrm{~nm}$, for different $\mathrm{CXO}$ solutions in the range $7.0 \times 10^{-6}$ to $7.0 \times 10^{-5} \mathrm{~mol} \mathrm{~L}^{-1}$. Therefore, the kinetics equation for reaction can correspond to: $\mathbf{v}=\mathbf{k}^{\prime}[\mathbf{C X O}]^{\mathbf{n}}$, where $\mathbf{k}^{\mathbf{\prime}}$ is the pseudo-rate constant and $\mathbf{n}$ is the reaction order. The logarithmic form of this equation is: $\log \mathbf{v}=\operatorname{logk}{ }^{\prime}+\mathbf{n} \log [\mathbf{C X O}$. The plot of the $\log \mathrm{v} v / \mathrm{s} \log [\mathrm{CXO}]$, allows evaluate the reaction order, the equation obtained was, $\log \mathrm{v}=0.7038$ $\log [\mathrm{CXO}]-0.7274 ; \mathrm{R}^{2}=0.9973$. Then, $\mathrm{k}^{\prime}=5.34 \mathrm{~s}^{-1}$ and the reaction is pseudofirst order $(\mathrm{n}=0.704 \sim 1)$ with respect to CXO.

\subsection{Evaluation of the kinetic methods}

The quantification of CXO was carried out according to the pseudo-first order rate equation: $\mathrm{v}=5.34 \mathrm{~s}^{-1}[\mathrm{CXO}]^{0.704}$. Many assays were carried out to determine of the CXO concentration using the rate data (rate law). Initial rate, constant rate and fixed time methods ${ }^{25,26}$ were tried and the selection of the kinetic method is based in the applicability, sensitivity, intercept and $\mathrm{R}^{2}$.
Initial rate. The initial rate kinetic method was evaluated by plotting the rate (at the beginning of the reaction at time $250 \mathrm{~s}$ ) v/s [CXO]. As it mentioned above the first step of the reaction was not rate determining (fast) and the tangents to the curves at previously defined value of time are not easy to draw. Eq. 1 shows the results obtained, these correspond to behavior of pseudo-zero order, and the value of $\mathrm{R}^{2}$ indicates a low linearity, this method was discarded.

$$
V_{0}=17.6 C+1.10 \times 10^{-4}\left(R^{2}=0.9641\right)
$$

Rate constant. Graphs of $\log \mathrm{A} v \mathrm{v} / \mathrm{s}$ time $(0-1800 \mathrm{~s})$ were plotted, for CXO concentration $([\mathrm{CXO}])$ in the range of $1.0 \times 10^{-6}$ to $13 \times 10^{-6} \mathrm{molL}^{-1}$ and presented linear behavior. To each of CXO concentrations the pseudo-first order rate constants $(\mathrm{K})$ were determined, multiplying the respective slopes by -2.303 . The equation obtained with the linear regression of $\mathrm{K} v / \mathrm{s}[\mathrm{CXO}]$ was:

$$
K=8.57 C-6.98 \times 10^{-4}\left(R^{2}=0.9853\right) . \quad \text { Eq.2 }
$$

From the linear regression, an unsatisfactory $\mathrm{R}^{2}$ value was obtained. The inconsistency in the rate values was due to that the reaction does not reach equilibrium in a short reaction time, so the dynamic range used influences obtaining data by this method, for this reason was discarded.

Fixed time. In this method, the absorbance (A) of the reactions corresponding to different $\mathrm{CXO}$ concentration $\left(1.0 \times 10^{-6}\right.$ to $\left.13 \times 10^{-6} \mathrm{~mol} \mathrm{~L}^{-1}\right)$ were measured at fixed times of 5,10,15,20,25 and $30 \mathrm{~min}$. Calibration plots of $\mathrm{A} \mathrm{v} / \mathrm{s}[\mathrm{CXO}]$ at each fixed time value were realized. For each fixed time value, the linear regression equations, the coefficients of determination and respective statistical parameters were obtained, such as variance, standard deviation, confidence limits. The slopes and intercepts are increased with time. Moreover, a t-student was performed considering a two-tailed t-test and n-2 degrees of freedom as a function of $r$. The values obtained are shown in Table 1. Considering a statistical null hypothesis $\mathrm{H}_{0}$, of no correlation between the CXO concentration and absorbance, all values of t-student obtained proved to be greater than the $t_{\text {crit }}\left(t_{\text {exp }}>t_{\text {crii }}\right)$ therefore the null hypothesis is rejected, concluding that there is linear correlation for each fixed time method. The results showed that the slopes and intercepts increase with time. The fixed time 30 min has: high slope value, lower variance implying lowest dispersion expected values in distribution, therefore based on the parameters studied 30 min was selected as the most suitable time for measurements and to develop the analytical method and its subsequent application in pharmaceutical formulations.

\subsection{Calibration curve and analytical parameters using CXO standards} solutions

After performing the optimization of experimental conditions, the fixed time (30 min) method was applied to the CXO determination. Linear regression analysis of the calibration data and measurements of 11 independent blanks (samples without analyte) were carried out, in order to obtain the detection and quantitation limits, LOD and LOQ, respectively (Table 2).

Using the proposed method in the range studied of drug concentrations and under experimental conditions optimized, was possible to obtain good sensitivity and lows LOD and LOQ, which would allow of the CXO determination in pharmaceutical samples. With three different concentrations of $\operatorname{CXO}\left(0.27,1.88\right.$ and $\left.3.49 \mathrm{mg} \mathrm{mL}^{-1}\right)$ the accuracy was evaluated. For the accuracy of the assays "intra-day" and "inter-day", were carried out for five consecutive days (Table 3). On the other hand the precision of the procedure was expressed as the relative standard deviation (RSD) and considering the same concentration levels were also obtained (Table 3). 
Table 1. Calibration curves and statistical parameters for different fixed times at room $\mathrm{T}^{\circ}$ and monitoring at $610 \mathrm{~nm}$.

\begin{tabular}{|c|c|c|c|c|c|c|}
\hline \multirow[b]{2}{*}{ Parameters } & \multicolumn{6}{|c|}{ Fixed time [min] } \\
\hline & 5 & 10 & 15 & 20 & 25 & 30 \\
\hline Concentration Range $\left[\mu \mathrm{g} \mathrm{mL}^{-1}\right]$ & $0.27-3.49$ & $0.27-3.49$ & $0.27-3.49$ & $0.27-3.49$ & $0.27-3.49$ & $0.27-3.49$ \\
\hline Linear Regression & $\begin{aligned} \mathrm{A} & =0.0245 \mathrm{C} \\
& +0.0212\end{aligned}$ & $\begin{aligned} \mathrm{A} & =0.0327 \mathrm{C} \\
& +0.0532\end{aligned}$ & $\begin{array}{c}\mathrm{A}=0.0348 \mathrm{C}+ \\
0.0657\end{array}$ & $\begin{aligned} \mathrm{A} & =0.0415 \mathrm{C} \\
& +0.0559\end{aligned}$ & $\begin{aligned} \mathrm{A} & =0.0522 \mathrm{C} \\
& +0.0315\end{aligned}$ & $\begin{aligned} \mathrm{A} & =0.0606 \mathrm{C} \\
& +0.0583\end{aligned}$ \\
\hline$S_{n}$ & $4.45 \times 10^{-3}$ & $3.80 \times 10^{-3}$ & $3.38 \times 10^{-3}$ & $3.04 \times 10^{-3}$ & $2.67 \times 10^{-3}$ & $1.89 \times 10^{-3}$ \\
\hline$\pm \mathrm{tS}_{\mathrm{n}}^{\sim}$ & $1.42 \times 10^{-2}$ & $1.21 \times 10^{-2}$ & $1.08 \times 10^{-2}$ & $9.67 \times 10^{-3}$ & $8.49 \times 10^{-3}$ & $6.02 \times 10^{-3}$ \\
\hline $\mathrm{S}_{\mathrm{m}}$ & $2.03 \times 10^{-3}$ & $1.73 \times 10^{-3}$ & $1.54 \times 10^{-3}$ & $1.38 \times 10^{-3}$ & $1.22 \times 10^{-3}$ & $8.61 \times 10^{-4}$ \\
\hline$\pm \mathrm{tS}_{\mathrm{m}}^{\sim}$ & $6.45 \times 10^{-3}$ & $5.51 \times 10^{-3}$ & $4.89 \times 10^{-3}$ & $4.40 \times 10^{-3}$ & $3.88 \times 10^{-3}$ & $2.74 \times 10^{-3}$ \\
\hline $\mathbf{R}^{2}$ & 0.9732 & 0.9889 & 0.9922 & 0.9956 & 0.9978 & 0.9992 \\
\hline Variance $\left(\mathrm{S}_{0}{ }^{2}\right)\left[\mu \mathrm{g} \mathrm{mL^{-1 }}\right]^{2}$ & $2.66 \times 10^{-5}$ & $1.94 \times 10^{-5}$ & $1.53 \times 10^{-5}$ & $1.24 \times 10^{-5}$ & $9.61 \times 10^{-6}$ & $4.80 \times 10^{-6}$ \\
\hline $\mathrm{S}_{0}^{*}\left[\mu \mathrm{g} \mathrm{mL}^{-1}\right]$ & $5.16 \times 10^{-3}$ & $4.41 \times 10^{-3}$ & $3.91 \times 10^{-3}$ & $3.52 \times 10^{-3}$ & $3.10 \times 10^{-3}$ & $2.19 \times 10^{-3}$ \\
\hline$t_{\text {exp }}$ & 10.4 & 16.3 & 19.5 & 26.1 & 36.9 & 61.2 \\
\hline
\end{tabular}

The value of student " $t$ " for $n-2$ degrees of freedom with a confidence level of $95 \%$ with $n=5$ ( $t_{\text {crit }}=3.182$ ).

$\sim \mathrm{tS}_{\mathrm{n}}=$ confidence limit for the intercept; $\sim \mathrm{tS}_{\mathrm{m}}=$ confidence limit for the slope. * $\mathrm{So}$ is the standard deviation of the curve.

Table 2. Analytical parameters for the CXO determination.

\begin{tabular}{|c|c|}
\hline Parameters & Values \\
\hline Linear Regression & $\mathrm{A}=6.06 \times 10^{-2} \mathrm{C}+5.83 \times 10^{-2}$ \\
\hline $\mathbf{R}^{\mathbf{2}}$ & 0.9992 \\
\hline $\mathbf{L O D} *\left(\boldsymbol{\mu g m L} \mathbf{H}^{-1}\right)$ & 0.07 \\
\hline $\mathbf{L O Q} *\left(\boldsymbol{\mu g m L} \mathbf{L}^{-1}\right)$ & 0.23 \\
\hline Concentration Range $\left(\boldsymbol{\mu} \mathbf{g} \mathbf{m L}^{-1}\right)$ & $0.23-10.7$ \\
\hline$\sigma($ Blanks $)$ & $1.42 \times 10^{-3}$ \\
\hline
\end{tabular}

* LOD: $3 \sigma / \mathrm{S}$; LOQ: 10б/S

Table 3. Results of the evaluation of precision and accuracy, by studies "intra-day" and "inter-day", using CXO standards solutions.

\begin{tabular}{|c|c|c|c|c|c|c|}
\hline \multicolumn{2}{|c|}{$\mathbf{C X O}\left(\mu \mathrm{g} \mathrm{mL}^{-1}\right)$} & \multicolumn{5}{|c|}{ "Intra-day" } \\
\hline Added & Found & $\sigma$ & Recovery (\%) & RSD (\%) & ES* & Confidence Limit \\
\hline 0.27 & 0.27 & $8.13 \times 10^{-3}$ & 101.3 & 3.0 & $4.06 \times 10^{-3}$ & $1.29 \times 10^{-2}$ \\
\hline 1.88 & 1.87 & $4.76 \times 10^{-2}$ & 99.6 & 2.5 & $2.38 \times 10^{-2}$ & $7.58 \times 10^{-2}$ \\
\hline 3.49 & 3.49 & $3.44 \times 10^{-2}$ & 100.0 & 1.0 & $1.72 \times 10^{-2}$ & $5.47 \times 10^{-2}$ \\
\hline \multicolumn{7}{|c|}{ "Inter-day" } \\
\hline Added & Found & $\sigma$ & Recovery (\%) & RSD (\%) & ES* & Confidence Limit \\
\hline 0.27 & 0.26 & $1.35 \times 10^{-2}$ & 98.4 & 5.1 & $6.74 \times 10^{-3}$ & $2.14 \times 10^{-2}$ \\
\hline 1.88 & 1.91 & $4.26 \times 10^{-2}$ & 101.9 & 2.2 & $2.13 \times 10^{-2}$ & $6.78 \times 10^{-2}$ \\
\hline 3.49 & 3.54 & $5.64 \times 10^{-2}$ & 101.5 & 1.6 & $2.82 \times 10^{-2}$ & $8.97 \times 10^{-2}$ \\
\hline
\end{tabular}

\section{*Error standard deviation}

$\dagger$ Limits by $95 \%$ and 3 degrees of freedom $(t=3.182)$

The recoveries were between 98 and $102 \%$, and show a satisfactory accuracy for kinetic-analytical methods evaluated. The precision for the different

concentrations studied was RSD $<5.0 \%(0.27$ except for the "inter-day" precision), these results indicated a satisfactory repeatability and intermediate precision, for the proposed quantitation.

\subsection{Validation}

To validate the proposed method (fixed time kinetic method at $30 \mathrm{~min}$ ), a synthetic sample of cream was prepared. For obtain standard deviation of the blanks, a portion of sample was used. Others portions were spiked with different analyte concentrations in order to obtain the calibration curves considering excipients and active ingredient. Then the assays "intra-day" and "inter-day" of a group of 30 blanks were realized, the measurements were carried out for five consecutive days, with these results the standard deviation was determined (Table 4). The analytical parameters were obtained through the respective linear regression and the measurements of the above blanks of the pharmaceutical formulation (only excipients), the results obtained are shown in Table 4. In order to assess the accuracy of the method, the recoveries were obtained using different drug concentrations $\left(1.07,2.68\right.$ y $\left.3.49 \mathrm{ug} \mathrm{mL}^{-1}\right)$. The precision of the method was evaluated by the relative standard deviation, considering the same analyte concentration levels and the respective blanks, for the accuracy of the assays "intra-day" and "inter-day", (Measured for five consecutive days). The results obtained of the analysis to assess the precision and accuracy of the method, "intra-day" and "inter-day" in synthetic samples 
are shown in Table 5. The maximum allowed for commercial use in cream CXO is $1 \%$, for commercial pharmaceutical products the excipients commonly used are: cetyl alcohol, monostearate of glycerol, liquid petrolatum and benzoic acid (preservative). The acceptable ranges used for each of these compounds are: $2-30 \%, 1-10 \%$, without requirement and $0.1-0.2 \%(\mathrm{w} / \mathrm{w})$, respectively ${ }^{27}$. The interfering studies were realized in the range of maximum and minimum allowed, finding that only benzoic acid $(\mathrm{AB})$ interfere in proportion, $\mathrm{AB}$ : $\mathrm{CXO}=1: 2$. The amounts of benzoic acid utilized in the synthetic samples $(0.33 \%)$ were above the recommended value in cream, but the results prove the suitability of proposed method to be applied in pharmaceutical formulations with other benzoic acid proportions.
Table 4. Analytical parameters for the CXO determination.

\begin{tabular}{|c|c|}
\hline Parameters & CXO \\
\hline Linear Regression & $\mathrm{A}=9.50 \times 10^{-2} \mathrm{C}+2.88 \times 10^{-2}$ \\
\hline $\mathbf{R}^{\mathbf{2}}$ & 0.9957 \\
\hline $\mathbf{L O D} *\left(\boldsymbol{\mu g m L} \mathbf{g m}^{-1}\right)$ & 0.095 \\
\hline $\mathbf{L O Q} *\left(\boldsymbol{\mu} \mathbf{g m L}^{-1}\right)$ & 0.32 \\
\hline Concentration Range $\left(\boldsymbol{\mu g} \mathbf{~ m L}^{-1}\right)$ & $0.32-10.0$ \\
\hline$\sigma($ Blanks $)$ & $3.0 \times 10^{-3}$ \\
\hline
\end{tabular}

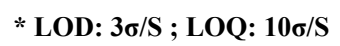

Table 5. Analysis to assess the precision and accuracy of the method, "intra-day" and "inter-day" in synthetic samples.

\begin{tabular}{|c|c|c|c|c|c|}
\hline \multicolumn{2}{|c|}{ CXO $\left(\mu \mathrm{gmL}^{-1}\right)$} & "Intra-day" \\
\hline Added & Found & Recovery (\%) & RSD (\%) & ES* & Confidence Limit $^{{ }^{*}}$ \\
\hline 1.07 & 1.08 & 100.6 & 3.70 & $1.97 \times 10^{-2}$ & $6.27 \times 10^{-2}$ \\
\hline 2.68 & 2.69 & 100.5 & 0.59 & $7.90 \times 10^{-3}$ & $2.51 \times 10^{-2}$ \\
\hline 3.49 & 3.45 & 98.9 & 1.07 & $1.84 \times 10^{-2}$ & $5.86 \times 10^{-2}$ \\
\hline \multicolumn{7}{|c|}{ "Inter-day” } \\
\hline Added & Found & Recovery (\%) & RSD (\%) & ES* $^{*}$ & Confidence Limit $^{\dagger}$ \\
\hline 1.07 & 1.06 & 99.8 & 4.4 & $2.37 \times 10^{-2}$ & $7.54 \times 10^{-2}$ \\
\hline 2.68 & 2.71 & 100.9 & 2.5 & $3.37 \times 10^{-2}$ & 0.107 \\
\hline 3.49 & 3.45 & 98.8 & 2.6 & $4.41 \times 10^{-2}$ & 0.140 \\
\hline
\end{tabular}

*Error standard deviation

$\dagger$ Limits by $95 \%$ and 3 degrees of freedom $(t=3,182)$

The differences in RSD values, between Tables 3 and 5 is inherent to the extraction process, which could affect, since all complex matrix can modify the final concentration of the analyte, for that reason the calibration curves must be carried in the matrix used, which also ensures adequate robustness to obtain the method developed.

\subsection{Application of the proposed method}

The developed kinetic spectrophotometric method for the CXO determination in commercial pharmaceutical formulation was applied (cream at $1 \% \mathrm{CXO}$ ). In all cases, the samples were prepared and analyzed according to respective procedure. The drug concentrations using the linear regression equation obtained in synthetic samples were calculated. For real samples an average value of $0.993 \mathrm{~g}$ of CXO, with $\mathrm{RSD}=3.0$, were found. These results prove that the common excipients do not interfere in the CXO determination, evidencing a high selectivity, although the method used the oxidation reaction with $\mathrm{KMnO}_{4}$, which is not selective. The values of recoveries support the suitability of the method for the CXO analysis in the proposed sample.

\section{CONCLUSIONS}

According to the optimization of kinetic of the oxidation reaction of CXO$\mathrm{KMnO}_{4}$ system by factorial screening and univariate method a $\mathrm{pH}=13.2$, $8 \times 10^{-4} \mathrm{~mol} \mathrm{~L}^{-1} \mathrm{KMnO}_{4}, 0.6 \mathrm{~mol} \mathrm{~L}^{-1} \mathrm{Na}_{2} \mathrm{SO}_{4}$, were found for 30 min of stirring and room $\mathrm{T}^{\circ}$. The molar relation $\mathrm{CXO}^{2} \mathrm{KMnO}_{4}$ was 1:2. The concentration of CXO was studied kinetically using different approaches: the reaction rate, initial rate, constant rate and fixed time methods. This last method at $30 \mathrm{~min}$ prove to be the most suitable, which was confirmed by satisfactory values of the correlation coefficients $\left(\mathrm{R}^{2}\right)$ and slopes obtained of calibration plots and can be easily applied in the determination of investigated fungicide in pure and pharmaceutical forms (cream), obtaining the results with $\operatorname{RSD}<5$ and $<4$, respectively. Furthermore provide the improving on selectivity, avoiding interference of colored or turbidity background of samples because it measures the increase in absorbance with time against the blank treated similarly. The proposed method is simple, sensitive and the results prove the suitability of method to be applied in pharmaceutical formulations with other benzoic acid proportions. Also do not require an elaborate extraction of the chromophore produced, expensive instruments and /or critical analytical reagents. This supports its use in routine quality control of drugs in pharmaceutical and industrial laboratories.

\section{ACKNOWLEDGEMENT}

The authors are grateful to the Fondo Nacional de Investigación en Ciencia y Tecnología (FONDECYT), Project $\mathrm{N}^{\circ} 1130398$ and CONICYT doctoral fellowship $\mathrm{N}^{\circ} 21120686$, for the financial support.

\section{REFERENCES}

1. A.K. Gupta, A.R. Skinner, Int. J. Dermatol. 42, 3, (2003)

2. Subissi A, Monti D, Togni G, Mailland F. Drugs. 70, 2133, (2010).

3. Junmei Li, Ye Jiang, Ting Sun, Shumeng Ren. J. of Pharma., and Biome. Anal. 47, 929, (2008).

4. www.drugs.com/ciclopirox/ciclopirox-olamine.html.

5. M. Niewerth, D. Kunze, B. Hube, Antimicrobial Agents and Chemotherapy 47 (6), 1805, (2003).

6. United States Pharmacopoeia 28, NF23, Convention, Inc., Rockville, MD, 470, (2005).

7. United States Pharmacopoeia 25, NF 20. Convention, Rockville, MD, 418, (2002).

8. K.H. Lehr, P. Damn, J. Chromatogr. B Biomed. Sciences and Appl. 339, 451, (1985).

9. L. Gagliardi, G. Multari, G. Cavazzutti, D. Tonelli, J. Liq. Chromatogr. Relat. Technol. 21, 2365, (1998).

10. A. Escarrone, C. Bittencourt, E. Primel, S. Caldas. Chromatographia, 67, 967, (2008).

11. F. Belliardo, A. Bertolino, G. Brandolo and C. Lucarelli. J. of Chromatography A 553, 41, (1991).

12. M. Ibrahim Walash, M. Salem Rizk, M. Ibrahim Eid, M. el Sayed Fathy. Acta Pharm. 56, 431, (2006).

13. L. Ferreira, F. Fabiana and A. Lucio, Electroanalysis 24, 961, (2012).

14. F. Ibrahim, N. El-Enany. J. of Pharma., and Biomed. Anal. 32, 353, (2003).

15. F. Ibrahim, N. El-Enany. Il Farmaco 58, 1313, (2003). 
16. Junmei Li, Ye Jiang, Ting Sun, Shumeng Ren, Journal of Pharmaceutical and Biomedical Analysis 47, 929, (2008).

17. F. Silva, F. Claudimir, L. do Lago and L. Angnes, Electrophoresis, 32, 900, (2011).

18. Wei Bu, Xiaoqing Fan, H. Sexton and I. Heyman, J. of Pharma. and Biomed. Anal. 51, 230, (2010).

19. Ayad M et al., European Journal of Chemistry, 4, 35, (2013).

20. Abdellaziz L. and Hosny M., Analytical Chemistry Insights, 6, 67, (2011).

21. A. Espinosa-Mansilla, M. Valenzuela, F. Salinas, Canada. F. Anal. Chim. Acta., 376, 193, (1998).
22. Khalil Farhadi and Hossein Sheikhloei Bonab J. Chin. Chem. Soc., 51, $743,(2004)$.

23. Oxidation in organic chemistry, Wiber K., Part A, Academic press New York, 17, (1965).

24. Rose, J. in Advanced Physicochemical Experiments, Pitman, London, UK, 67, (1964).

25. G. Theodoridisa, E. H. M. Kosterb and G. J. de Jong. J. of Chromatography B 745, 49, (2000).

26. Fábio R. and P. Rocha. Quim. Nova, 27, 807, (2004).

27. HandBook of Pharmaceutical Excipients $6^{\text {th }}$ ed., Rowe R., Sheskey P. and Quinn M., APHA, 2009. 